Tohoku J. Exp. Med., 2008, 215, 227-236

\title{
Liver-Specific Silencing of the Human Gene Encoding Succinyl-CoA: 3-Ketoacid CoA Transferase
}

\author{
Kenji E. Orit, ${ }^{1}$ Toshiyuki Fukao, ${ }^{1}$ Xiang-Qian Song, ${ }^{1}$ Grant A. Mitchell ${ }^{2}$ and \\ NAOMI KONDO ${ }^{1}$ \\ ${ }^{1}$ Department of Pediatrics, Graduate School of Medicine Gifu University, Gifu, Japan \\ ${ }^{2}$ Service de Genetique Medicale, Hopital Sainte-Justine, Montréal, Québec, Canada
}

\begin{abstract}
The human succinyl-CoA: 3-ketoacid CoA transferase (SCOT) gene encodes the ketolytic enzyme that functions in the mitochondrial matrix. The activation of acetoacetate to acetoacetyl-CoA by SCOT is essential for the use of ketone bodies as an energy source. The ketolytic capacity of tissues is proportional to their level of SCOT activity. Normal hepatocytes, the site of ketone body synthesis, have no detectable SCOT protein. The absence of SCOT in hepatocytes is an important element in energy metabolism, suppressing ketolysis in the liver. To study the tissue-specific silencing of SCOT expression, we analyzed the promoter function of SCOT gene in three different human cell lines. Immunoblot analysis showed that SCOT protein was detectable in HeLa cervical cancer cells and Chang liver cells. However, SCOT protein was not detected in HepG2 hepatoma cells and liver tissues, indicating that HepG2 hepatoma cells maintain the characteristics of liver cells in the ketone body metabolism. Luciferase reporter assays in HeLa and Chang liver cells showed that the 361-bp proximal region of the SCOT gene was responsible for the basal promoter activity and contained two GC boxes, each of which was bound in vitro by Sp1, a ubiquitously expressed transcription factor. These results suggest that these GC boxes may be important for SCOT gene expression. Moreover, the region between -2168 and -361 appeared to inhibit the SCOT promoter activity in HepG2 cells. Thus, liverspecific silencing of the SCOT gene expression may be mediated in part by its 5 '-flanking sequence. - Succinyl-CoA: 3-ketoacid CoA transferase; Gene regulation; Sp1.
\end{abstract}

Tohoku J. Exp. Med., 2008, 215 (3), 227-236.

(C) 2008 Tohoku University Medical Press

Ketone bodies are important vectors of energy transfer from the liver to extrahepatic tissues, especially when glucose is in short supply (Mitchell and Fukao 2001). Succinyl-CoA: 3 ketoacid-CoA transferase (SCOT; EC2.8.3.5; locus symbol $O X C T$ ) catalyzes the rate-determining step of ketone body utilization (ketolysis) in extrahepatic tissues. SCOT protein is abundant in heart, brain, and kidney and has been detected in all extrahepatic tissues tested (Fukao et al. 1997). The ketolytic capacity of tissues is proportional to their level of SCOT activity (Mitchell and Fukao 2001).

SCOT gene expression is almost completely suppressed in human liver, the site of ketone body synthesis (Fukao et al. 1997). This can be viewed

Received October 1, 2007; revision accepted for publication May 27, 2008.

Correspondence: Kenji E. Orii, Department of Pediatrics, Graduate School of Medicine Gifu University, 1-1 Yanagido, 501-1194 Gifu, Japan.

e-mail: kenjior-gif@umin.ac.jp 
as a mechanism to avoid futile cycling. Interestingly, rat hepatoma cell lines exhibit various degrees of SCOT protein expression while SCOT protein was scarcely detected in rat hepatocytes (Zhang et al. 1990) or in human hepatocytes (Fukao et al. 1997). Presumably, this may allow hepatoma cells to use ketone bodies as an energy source.

Hereditary SCOT deficiency is one cause of ketoacidosis and, typically, elevated serum levels of ketone bodies are present, even when the patient is well nourished and not acutely ill. Molecular analyses have been reported in some SCOT deficient patients (Kassovska-Bratinova et al. 1996; Song et al. 1998; Fukao et al. 2000).

We cloned human SCOT cDNA (KassovskaBratinova et al. 1996) and the human SCOT gene and reported its structural organization (Fukao et al. 2000). To better understand the physiological and pathological expression of the SCOT gene, we, herein, examined the 5'-flanking region of the SCOT gene. We determined the sequence of the 5 '-flanking region, identified transcriptional elements and characterized their effects on transcriptional regulation.

\section{Material and Methods}

Enzyme assay and immunoblot analysis

A small amount of human autopsy liver (as described by Fukao et al. 1997) was freeze-thawed and homogenized and cultured cells were sonicated, in 10

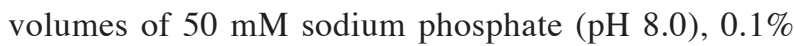
Triton X-100, and then centrifuged at $10,000 \times g$ for 10 min. Protein concentration was determined in the supernatant by the method of Lowry (Lowry et al. 1951), using BSA as a standard. Assays for acetoacetyl-CoA thiolase and for SCOT were as previously described (Williamson et al. 1971; Sakazaki et al. 1995), using acetoacetyl-CoA as a substrate and measuring its disappearance spectrophotometrically. Immunoblot analysis was performed as previously described (Song et al. 1997).

Quantitative reverse transcriptase-polymerase chain reaction ( $R T-P C R)$

Quantitative PCR was performed to determine the level of SCOT mRNA (Tashita et al. 1998; Fukao et al. 1999). First strand synthesis from $5 \mu \mathrm{g}$ of total RNA using a SCOT specific antisense primer was performed as described (Kassovska-Bratinova et al. 1996). A fragment of $406 \mathrm{bp}$, from nucleotides 1181 to 1586 , was amplified using a sense primer 1 from exon 13 and an antisense primer 2 from exon 17: primer $1 ; 5^{\prime}-{ }^{1181}$ TCGAT CTGACAATGCTAGGA ${ }^{1200}-3^{\prime}$, primer $2 ; 5^{\prime}-{ }^{1586}$ AGCCT GGTACAAATATCCATA ${ }^{1566}-3^{\prime}$. Nucleotides are numbered with the $\mathrm{A}$ of the initiator Met codon designated as nucleotide 1. Cycling conditions were as follows: $94^{\circ} \mathrm{C}$ for $1 \mathrm{~min}, 54^{\circ} \mathrm{C}$ for $2 \mathrm{~min}$, and $72^{\circ} \mathrm{C}$ for $2 \mathrm{~min}$ for 35 cycles. A competitor DNA of $290 \mathrm{bp}$ for the above cDNA fragment was made using a 249 bp human mitochondrial acetoacetyl-CoA thiolase (T2) cDNA fragment -40 - 199 as a template. This T2 cDNA fragment was amplified using T2 sense primer, which has a $5^{\prime}$ sequence tag of the above SCOT primer 1, and T2 antisense primer with a $5^{\prime}$ tag of the SCOT primer 2.

An equivalent point is reached when target SCOT cDNA (406 bp) is amplified to the same extent as competitor DNA (290 bp) allowing for quantification of mRNA. Amplification was performed with an amount of cDNA corresponding to $0.0125 \mu \mathrm{g}$ of RNA containing 1 $\mu 1$ of a series of 3 -fold dilutions of the competitor DNA from 270 to 0.125 attomoles.

Cloning and sequencing of the $5^{\prime}$ flanking region of the human SCOT gene.

The P1 clone 3977 contains exons 1 to 13 of the human SCOT gene (Fukao et al. 2000). We screened for SCOT gene fragments containing the $5^{\prime}$ flanking region using Southern blotting with exon 1 of the human SCOT gene as a probe. Positive fragments were subcloned to Bluescript plasmid vectors. A PstI fragment of about 4 $\mathrm{kb}$ included exon 1 and $3.8 \mathrm{~kb}$ of $5^{\prime}$ flanking sequence. Deletion fragments were obtained with Exo III/Mung Bean Deletion Kit (TOYOBO, Tokyo) and sequenced.

\section{Primer extension}

An antisense primer $3\left(5^{\prime}{ }^{+37}\right.$ CTCAAAATCCTCTC $\left.\mathrm{CTCCGG}^{+56}-3^{\prime}\right)$ was end labeled with $\left[\gamma^{-32} \mathrm{P}\right] \mathrm{dATP}$, using T4 kinase. Primer extension was performed as described (Sambrook et al. 1989), using $50 \mu \mathrm{g}$ of total RNA isolated from human kidney and from human fibroblasts. The plasmid, including the Pst I fragment of $4 \mathrm{~kb}$, was also sequenced with the same end-labeled primer. Products of primer extension and sequencing reactions were electrophoresed on $6 \%$ denatured polyacrylamide gels. 
Luciferase-promoter constructs and site-directed mutagenesis

Luciferase-promoter constructs were made using pGV-B2 luciferase reporter gene plasmid (Nippon Gene, Tokyo). Nucleotides are numbered here with the major transcription start site being designated +1 (Fig. 3). A fragment spanning nucleotides -407 to +56 was amplified using a sense primer $4\left(5^{\prime}-{ }^{-407}\right.$ AAAGCAACAAGCT TGGCGGG $\left.^{-388}-3^{\prime}\right)$ and an antisense primer $5\left(5^{\prime}\right.$-GGGC $\underline{\text { CATGG }}^{+56}$ CCGGAGGAGAGGATTTTGAG $^{+37}-3^{\prime}$; the underlined sequence is a NcoI tag) and subcloned into HindIII and NcoI sites of pGV-B2 luciferase reporter gene plasmid (termed pLUC-9). Sequence accuracy of the amplified fragment was confirmed by sequencing. pLUC-1 was made as follows: the HindIII/ SacI fragment in pLUC-9 was replaced by HindIII/ SacI digested deletion fragments, which were generated for sequencing, as described above.

Insert DNAs in pLUC-2, 3, 4, 5, 6, 7 and 8 were made by PCR amplification using primers 6-12 (containing a $S a c$ I tag), respectively, and primer 5; cloned DNA fragments were sequenced. primer $6 ; 5^{\prime}$-TTTGAGCTC ${ }^{-361}$ GAACCCTAGGCCAAGACTCA ${ }^{-342}-3^{\prime}$, primer $7 ; 5^{\prime}$ -TTTGAGCTC ${ }^{-325}$ AGGCGGCCACCAGC $^{-312}-3^{\prime}$, primer 8; 5' -TTTGAGCTC- $^{290}{ }^{2}$ TGACAGAAGGGCTGTA ${ }^{-275}-3^{\prime}$,

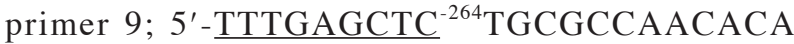
$\mathrm{GCTGC}^{-248}-3^{\prime}$, primer $10 ; 5^{\prime}$ - TTTGAGCTC ${ }^{-193}{ }^{\text {TGCACAGAGCCTCTTCT }}{ }^{-177}-3^{\prime}$, primer $11 ; 5$ -TTTGAGCTC ${ }^{-162}$ CGCCCAGCCTCACTTC $^{-147}-3^{\prime}$, primer $12 ; 5^{\prime}$-TTTGAGCTC- ${ }^{112}{ }^{\text {CGTGCGGGCTCG }}{ }^{-101}$. $\left.3^{\prime}\right)$. Underlined sequences were SacI tag sequences. Site-directed mutagenesis was performed on the pLUC-1 plasmid using the QuickChange Site-Directed Mutagenesis Kit (Stratagene, La Jolla, CA, USA), and confirmed by sequencing. pLUC-m1 and $\mathrm{m} 2$ were made using primers 13 and 14, respectively: primer $13 ; 5^{\prime}-{ }^{-71} \mathrm{G}$ TCGAGCCTCCAGCC $\underline{\mathbf{A} \mathbf{A A A} \text { AGGGTTTCC }}{ }^{-44}-3^{\prime}$, primer $14 ; 5^{\prime-173}$ CGCCGGGGCCC $\underline{\mathbf{A A A A} A C A G C C T C A C}$ $\mathrm{T}^{149}-3^{\prime}$. Underlined sequences were mutated. Plasmids were purified by $\mathrm{CsCl}$ density gradient centrifugation (Sambrook et al. 1989).

\section{Cell culture media and conditions}

HepG2, HeLa, Hle and Chang liver cells were grown in Dulbecco's modified Eagle's Medium supplemented with $10 \%$ fetal bovine serum (Life Technologies, Rockville, MD, USA).

HepG2 and Hle cells are derived from human hepatoma. Chang liver cells are derived from human liver cells. HeLa cells are derived from human uterine cervical cancer cells.

\section{Transfections and luciferase assays}

We used a Dual-luciferase assay system (Nippon Gene). Firefly and Renilla luciferases, because of their distinct evolutionary origins, have dissimilar enzyme structures and substrate requirements. These differences make it possible to selectively discriminate between their respective bioluminescent reactions. pRL-CMV was the internal control that contains the CMV enhancer and early promoter elements to provide high-level expression of Renilla luciferase in co-transfected mammalian cells. Firefly luciferase-promoter constructs were made using pGV-B2 luciferase reporter gene plasmid (Nippon Gene). 20-24 h before transfection, cells were replated into 60 $\mathrm{mm}$ dishes. Cells were cotransfected with $6 \mu \mathrm{g}$ of reporter construct and $1 \mu \mathrm{g}$ of LUC control vector (pRL-CMV) using a Gene Pulsar apparatus (BioRad, Hercules, CA, USA) and LipofectAMINE 2000 (Life Technologies). Luciferase assay was performed using The PicaGene Dual SeaPansy ${ }^{\mathrm{TM}}$ Luciferase Kit (TOYO INK, Tokyo) and a Lumat LB 9507 (EG\&G, Berthold, Germany) luminometer. Statistical analyses were done using the Kruskal-Wallis test and the Bonferroni/Dunn test.

Electrophoretic mobility shift and antibody supershift assay Nuclear extracts from HeLa cells were prepared as described (Dignam et al. 1983). Two double-stranded synthetic oligonucleotides corresponding to nucleotides -44 to -71 and -151 to -177 of the $5^{\prime}$ flanking region of the SCOT gene with 5'-GC overhangs were used as probes 1 and 2, respectively (Fig. 3). Electrophoretic mobility shift assays were done as described (Lavin et al. 1988), but with minor modification (Miyamoto et al. 1993). ${ }^{32} \mathrm{P}-$ End-labeled probes 1 and 2 (5 fmole of oligonucleotide, $15,000-20,000 \mathrm{cpm}$ ) were incubated for 15 min with $5 \mu \mathrm{g}$ of nuclear extract from HeLa cells at room temperature in $10 \mu \mathrm{l}$ of reaction mixture containing 15 mM Hepes-KOH (pH 7.1) buffer, 0.3 mM EDTA, 60 $\mathrm{mM} \mathrm{KCl}, 0.1 \mu \mathrm{g}$ of poly (DI-DC), $1.2 \mathrm{mM}$ dithiothreitol, $0.72 \mathrm{mM} \mathrm{MgCl}_{2}$, and $10 \%$ glycerol. These reactions were electrophoresed using $5 \%$ polyacrylamide gels in Tris-glycine buffer (50 mM Tris, $380 \mathrm{mM}$ glycine, and 2 $\mathrm{mM}$ EDTA) at $200 \mathrm{~V}$ for $90 \mathrm{~min}$ at $4{ }^{\circ} \mathrm{C}$. The gel was analyzed by autoradiography. Competition experiments were performed using oligonucleotides as follows (only one strand is shown): Sp1 consensus oligonucleotide, 5'- 
ATTCGATCGGGGCGGGGCGCGAGC-3'; AP1 consensus oligonucleotide, 5'-CGCTTGATGAGTCAGCCG CTAA- $3^{\prime}$. The sequences of mutated probes $1 \mathrm{~m}$ and $2 \mathrm{~m}$ are as follows: probe $1 \mathrm{~m} ; 5^{\prime}-{ }^{-71}$ GTCGAGCCTCCAGCC AAAACGGGTTTC ${ }^{-44}-3^{\prime}$, probe $2 \mathrm{~m} ; 5^{\prime}-{ }^{-177}$ TCCCCGCC GGGGCCCAAAACAGCCTCA ${ }^{-151}-3^{\prime}$. The positions of the upper strand mutations are underlined.

For the antibody supershift assay, we added $2 \mu 1$ of commercially available affinity-purified rabbit polyclonal antibody against human Sp1 (Santa Cruz Biotechnology, Santa Cruz, CA, USA) to $10 \mu 1$ of reaction mixture with $5 \mu \mathrm{g}$ of HeLa cell nuclear extract. After a 5 min incubation, $10,000 \mathrm{cpm}$ of ${ }^{32} \mathrm{P}$-labeled probe was added. Binding was performed for $20 \mathrm{~min}$ at room temperature, and the reactions were loaded on a $10 \%$ glycerol, $5 \%$ polyacrylamide gel and run at $40 \mathrm{~mA}$ in $1 \mathrm{x}$ Tris-borate EDTA buffer at $10^{\circ} \mathrm{C}$. The gel was analyzed by autoradiography.

\section{Results}

SCOT activity and Immunoblot analysis in HeLa and hepatoma cells

SCOT activities of HeLa cells, Hle cells, Chang liver cells, and HepG2 cells were 15.5, 9.7, 11.9 , and $3.3 \mathrm{nmol} / \mathrm{min} / \mathrm{mg}$ protein, respectively. The SCOT activity in HepG2 could be regarded as a background activity since the level was similar to that of SCOT-null fibroblasts (KassovskaBratinova et al. 1996; Song et al. 1998; Fukao et al. 2000). The ratios of SCOT activity to acetoacetyl-CoA thiolase activity in the presence of potassium ion were $0.44,0.46,0.40$, and 0.023 , in HeLa, Hle, Chang liver, and HepG2 cell lines, respectively.

As previously reported (Fukao et al. 1997) SCOT protein was not detected in human liver extracts, whereas T2 protein was abundant (Fig. 1). In HeLa cells derived from human cervical cancer, SCOT protein was abundant. Among the human hepatoma cell lines, SCOT protein was not detected in HepG2 cells, but was clearly present in Chang liver cells and in Hle cells, similar to reports of rat hepatoma cell lines with measurable SCOT protein expression (Zhang et al. 1990). T2 protein was present at similar levels in these cell lines.

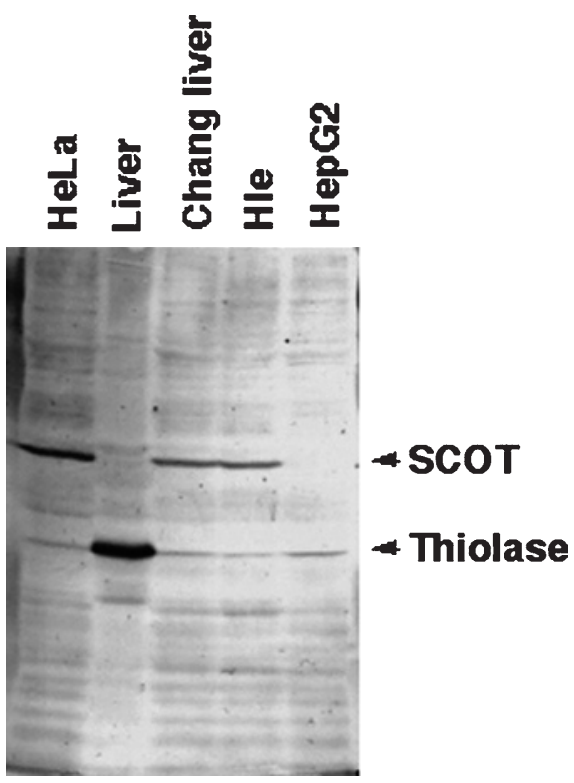

Fig. 1. Immunoblot analysis of various cell lines and liver. For cell extracts, $40 \mu \mathrm{g}$ of protein were analyzed; for liver extract, $15 \mu \mathrm{g}$ of protein was applied. Lanes: HeLa, HeLa cells; Chang liver, Chang liver cells; Hle, Hle cells; HepG2, HepG2 cells; Liver, Liver tissue. A mixture of anti-rat T2 antibody and anti-human SCOT antibody was used as the primary antibody. The positions of T2 and SCOT subunits are indicated by arrows.

Quantitative RT-PCR for the SCOT Transcript

We previously reported that neither SCOT mRNA nor SCOT protein were detectable in human liver (Fukao et al. 1997). We performed quantitative PCR to address whether the differences among SCOT protein levels in HeLa cells and in several hepatoma cell lines were due to differences among SCOT mRNA levels.

In this study, we used HeLa, Chang liver and HepG2 cells. As shown in Fig. 2, an equivalent point was reached at 2, 400 attomoles/ $\mu \mathrm{g}$ RNA for HeLa cells; between 2400-800 attomoles/ $\mu$ g RNA for Chang liver cells, and between 10 to 30 attomoles $\mu \mathrm{g}$ RNA for HepG 2 cells. Hence, in Chang liver cells, the level of SCOT gene expression was almost as great as in HeLa cells, whereas SCOT gene expression in HepG2 cells was low, as in primary hepatocytes. The SCOT mRNA level in HepG2 cells was about 1/27-1/80 of that in Chang liver cells. 

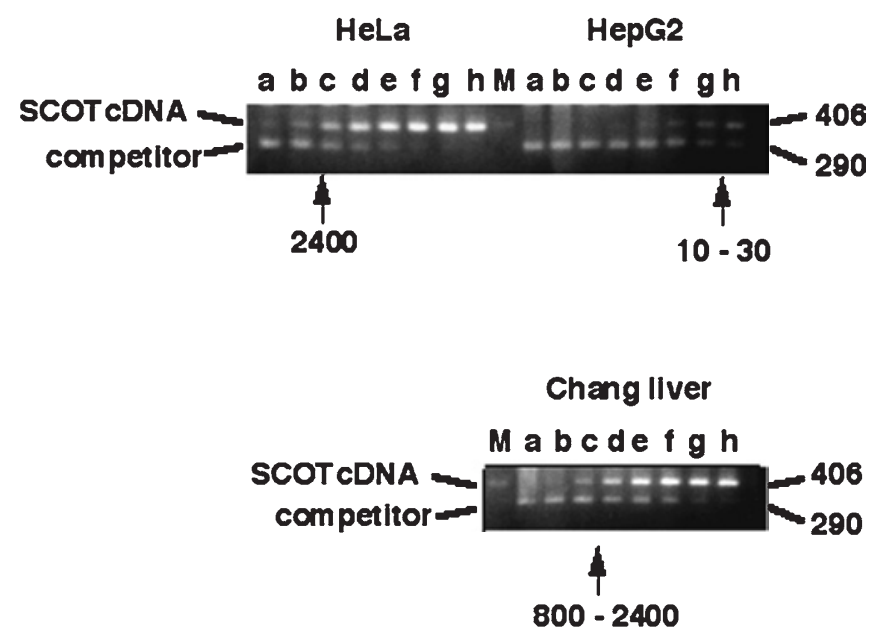

Fig. 2. RT-PCR quantitation of the SCOT transcript. Chang liver cells, HeLa cells and HepG2 cells were examined. Each template contained the same amount of cDNA. The amounts of competitor cDNA transcribed from 1 microgram of RNA are as follows; lanes a through h; a 21,600, b 7,200, c 2,400, d 800, e 270, f 90, g 30, h 10 attomoles. Points at which target SCOT cDNA and competitor DNA were almost equivalent are indicated by arrows.

\section{5 flanking region sequence}

The sequence of $2168 \mathrm{bp}$ of the 5'-flanking region was determined (partial sequence is at DNA Data Bank of Japan-EMBL-GenBank nucleotide sequence database, accession number AB072192). The transcription initiation sites of the SCOT gene were determined by primer extension experiments (data not shown). There were three major bands (56 bp, $97 \mathrm{bp}$, and $127 \mathrm{bp}$ ) in human kidney, and one band (56 bp) in control fibroblasts. The $56 \mathrm{bp}$ band is the major product in both RNAs (data not shown). The major tran-

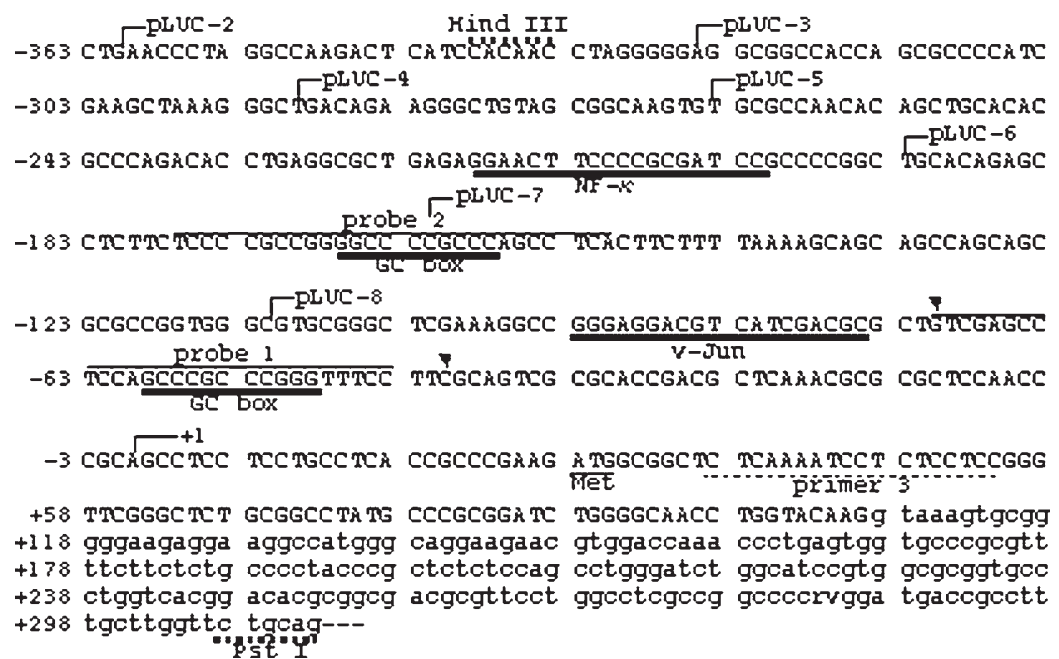

Fig. 3. Nucleotide sequence of the $5^{\prime}$ flanking region of the SCOT gene. Intronic regions are shown by small letters. The translation initiation codon is underlined. Arrowheads are the minor transcription initiation sites, as determined by primer extension analysis (data not shown). Nucleotide positions are numbered from the major transcription initiation site, designated as +1 . Also indicated are the HindIII and PstI cloning sites, the $5^{\prime}$ extremities of the pLUC series of clones and putative transcription control sequences. The sequence of primer 3 is underlined. 
scription initiation site of the SCOT gene corresponds to the $5^{\prime}$ end of the cDNA clone, as shown by arrow +1 in Fig. 3. Two other sites corresponded to positions -41 and -71 , respectively (Fig. 3). Hereafter, we will number SCOT nucleotide positions from the major transcription initiation site that is designated nucleotide 1 .

The promoter region of the SCOT gene does not have TATA-like cis-elements, but it has two GC boxes and a v-Jun consensus sequence near the major transcription start site.

GC-contents of this $5^{\prime}$ flanking region were more than $50 \%$ between residues +1 to $-400 \mathrm{bp}$, but were less than $50 \%$ from -400 to -2168 .
Characterization of the SCOT promoter in HeLa cells

A fragment of 2224 bp (from -2168 to +56 , pLUC-1) was cloned upstream of the luciferase cDNA (LUC cDNA, Fig. 4A). The constructs were transfected to these cells by electroporation. Activities relative to those of cotransfected Renilla luciferase vector (pRL-CMV) were calculated and are shown in Fig. 4. The pLUC-2 deleted from -2168 to -362 retained almost the same high-level luciferase activity as pLUC-1, however, further truncation constructs reduced luciferase activities. Hence the basic SCOT promoter locates within this $361 \mathrm{bp}$, which includes two GC boxes. There were several significant differ-

$\mathbf{B}$
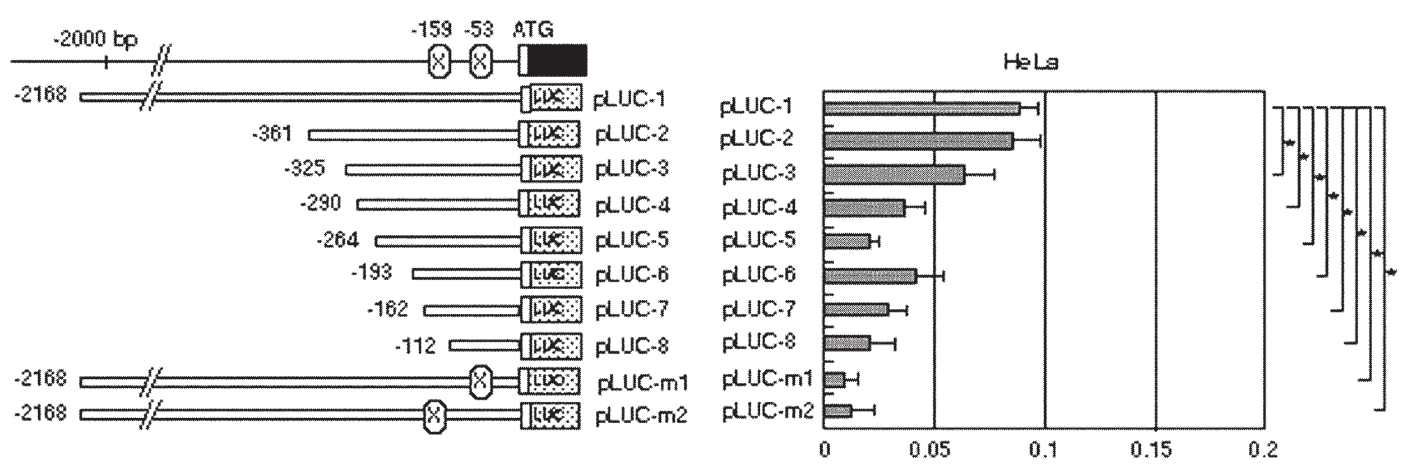

C

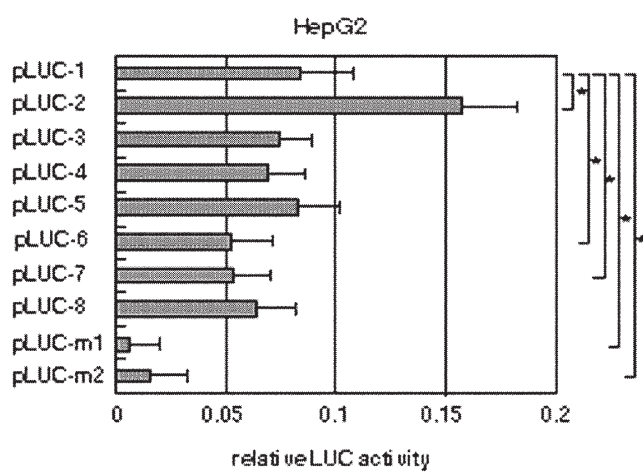

D

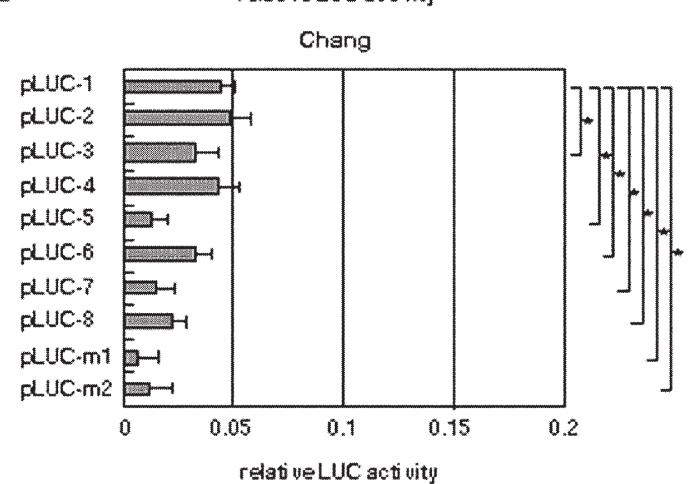

Fig. 4. Luciferase reporter assay. A) Various Firefly LUC vector constructs are shown on the left. Nucleotide positions are numbered relative to the major transcription initiation site, +1 . The two GC boxes of pLUC-1 vector were mutated, pLUC-m1 and-m2. B) D) Cotransfection of the Firefly luciferase vector with deletion mutants (pLUC-1 pLUC-8) or with mutated GC boxes (pLUC-m1 and pLUC-m2) and Renilla luciferase internal control vector (pRL-CMV) into each cell line was performed in triplicate. Means of the ratio of relative Firefly luciferase activity to cotransfected pRL-CMV Renilla luciferase activity were calculated and are shown on the right. Significant differences between pLUC-1 and other constructs are indicated $\left({ }^{*} p<0.045\right)$ using the KruskalWallis test and the Bonferroni/Dunn test. Note the significant difference between pLUC-1 and pLUC-2 in HepG2 cells. 
ences between pLUC-1 luciferase activity and that of other deletion mutants (pLUC-2 pLUC-8) or mutated GC boxes (pLUC-m1 and pLUC-m2) in HeLa cells, HepG2 cells, and Chang liver cells.

\section{Mutation analysis at $G C$ boxes}

To examine the regulative function of GC boxes as the basic promoter, mutations were introduced at each GC box in pLUC-1 (pLUC-m1 and $\mathrm{m} 2$ ). As shown in Fig. 4 reported activity from these mutant constructs were reduced 4- to 5-fold compared to pLUC-1.

\section{Luciferase-reporter assay in hepatoma cell lines}

As described, we characterized the 5'-flank- ing region using a luciferase-reporter assay in HeLa cells. Because primary cultures of human hepatic cells were not available, HepG2 cells were used as possible surrogates since SCOT gene expression was very low and SCOT protein level was beneath the detection limit in immunoblots. Chang liver cells could represent hepatoma cells which gain SCOT expression. Hence it is interesting to contrast the promoter activities in these cells.

As shown in Fig. $4 \mathrm{C}$ and D, there are some variations among constructs and among cell lines. pLUC-2 activity in HepG2 cells was significantly higher than pLUC-1 activity in HepG2 cells, but not in Chang liver cells. No other obvious difference was observed between the luciferase activi-

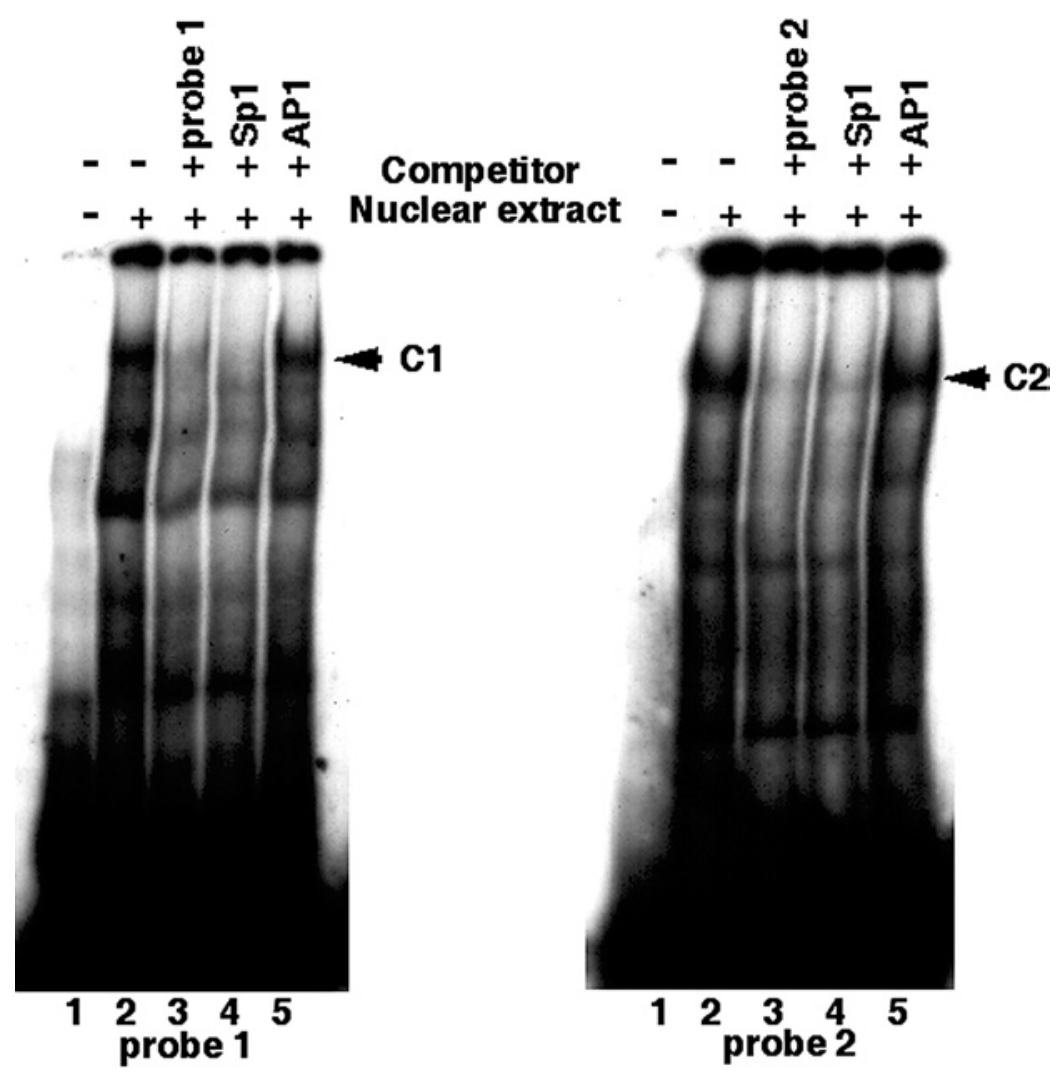

Fig. 5. Gel mobility shift assays. To confirm the binding of nuclear extract to the promoter region, gel mobility shift assays were done using ${ }^{32} \mathrm{P}$-labeled synthetic oligonucleotides, probes 1 and 2 , for the two GC boxes, respectively. $5 \mu \mathrm{g}$ of protein of nuclear extract from HeLa cells were used. Lane 1, labeled probe only; Lane 2, labeled probe and nuclear extract. A 400-fold molar excess of unlabeled probe 1 or 2 (lane 3), and oligonucleotides of consensus binding sites of Sp1 (lanes 4), and AP1 (lanes 5) were used as competitors. Major complexes, C1 and C2, were not detected in the presence of unlabeled Sp1-consensus oligonucleotide. 
ties of HepG2 and Chang liver cells. The data suggest the presence of a potential silencer that is functional only in HepG2 cells. This indicated that another transcriptional mechanism, for example, other transcriptional factors, methylation, or some suppressor sites act as a tissue-specific regulator.

Transcriptional factors binding to the promoter region

Gel mobility shift assays were done using ${ }^{32} \mathrm{P}$-labeled synthetic oligonucleotides corresponding to the two GC boxes to confirm binding of nuclear proteins to probes 1 and 2, respectively. When unlabeled oligonucleotides (probes 1 and 2) were used as competitors, the bands of complexes $\mathrm{C} 1$ and $\mathrm{C} 2$ disappeared, respectively (Fig. 5). Both sequences contain consensus-binding sites for transcription factor Sp1 (Fig. 3). When a 400-fold molar excess of oligonucleotides of the $\mathrm{Sp} 1$ or the AP1 consensus sites were used as competitors, the Sp1 consensus oligonucleotide specifically competed, reducing the formation of complexes $\mathrm{C} 1$ and $\mathrm{C} 2$; AP1 did not compete.

\section{Supershift analysis}

Sp1 binding to probes 1 and 2 was confirmed in supershift experiments using polyclonal antiSp1 antibody. Electrophoretic mobilities of complexes $\mathrm{C} 1$ and $\mathrm{C} 2$ were slower in the presence of an antibody, (Fig. 6). These data suggest that the basic promoter of the human SCOT gene is located from -361 to +56 and is driven by two GC boxes, and that some additional upstream elements affect gene expression.

\section{DiscuSSION}

The activation of acetoacetate to acetoacetylCoA by SCOT is essential for the use of ketone bodies as an energy source (Mitchell and Fukao 2001). In normal hepatocytes, SCOT gene expression is suppressed almost completely (Fukao et al. 1997). The absence of SCOT in hepatocytes is an important element in energy metabolism, suppressing ketolysis in the liver that might otherwise create a futile cycle and interfere with the efficiency of ketogenesis. In contrast, all

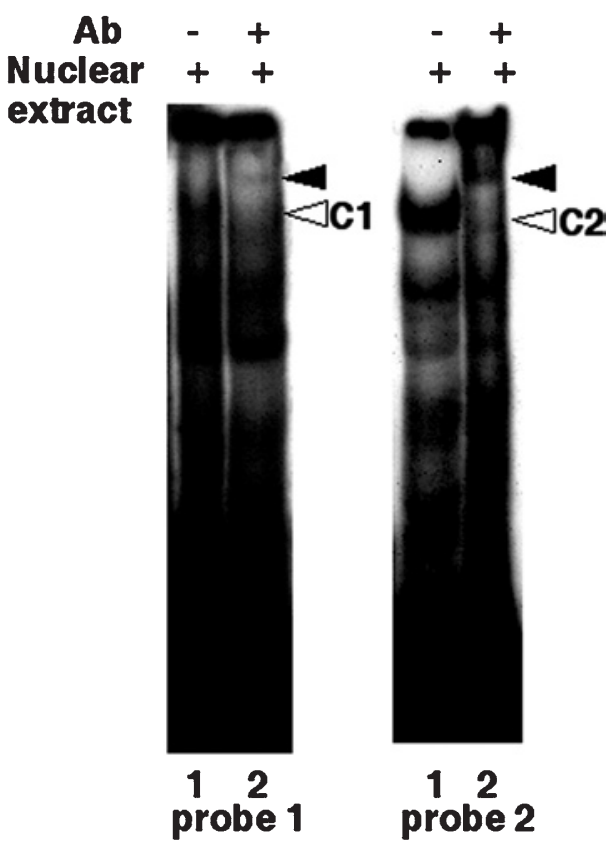

Fig. 6. Supershift assay. Supershift assay was performed using $1 \mu \mathrm{g}$ of anti-human $\mathrm{Sp} 1$ antibody. The positions of complexes $\mathrm{C} 1$ and $\mathrm{C} 2$ are indicated on the right. Open arrowheads indicate the position of probe without antibodies. Closed arrowheads indicate the position of complexes in the presence of antibody (Ab). Lane 1, nuclear extract and labeled probe; Lane 2, nuclear extract, labeled probe, and Sp1 antibody.

extrahepatic tissues tested have SCOT expression to various degrees, myocardium $>$ brain, kidney, adrenal glands $>$ other tissues (Fukao et al. 1997). In addition to the tissue-specific regulation of SCOT, physiological induction of SCOT gene expression may occur. The activity of SCOT is greater in 3 10-year-old subjects than in infants (0 2 years old) than adults aged 37 69 -year-old (Page et al. 1971). Since the SCOT step is ratedetermining for ketolysis, under conditions of abundant circulating ketone bodies, its level is thought to reflect the ketolytic capacity of tissues. Therefore, understanding SCOT gene regulation is important for understanding ketone body metabolism.

An interesting aspect of SCOT gene regulation is that some hepatoma cell lines have detectable SCOT expression. Several lines of evidence showed that some rat hepatoma cell lines 
expressed SCOT protein to some extent (Fenselau et al. 1976; Fields et al. 1981; Zhang et al. 1990). Zhang et al. (1990) suggested that differences in SCOT activities in different hepatoma cell lines were due to differences in SCOT mRNA quantities. We herein clearly showed that human hepatoma, Chang liver and Hle cell lines, also contain SCOT protein and that this dysregulation occurred at the mRNA level. However, another hepatoma cell line, HepG2, retained an almost complete suppression of the SCOT gene, a characteristic of normal differentiated hepatocytes. Chang liver cells expressed a similar level of SCOT to that of the non-hepatocyte-derived HeLa cells, 27-80 fold greater than the SCOT level of HepG2 cells. SCOT-expression in hepatoma cells may confer a proliferative advantage since SCOT expression would allow these cells to use ketone bodies as an alternative energy source. We have found that PHA-stimulated or EB-virus transformed lymphoblasts and SV40 transformed fibroblasts also have 2-3 fold higher levels of SCOT protein than normal lymphocytes and fibroblasts (Fukao et al., unpublished observations).

We herein cloned $2.2 \mathrm{~kb}$ of the $5^{\prime}$ flanking region of the human SCOT gene and clearly showed that its basic promoter region is contained within $361 \mathrm{bp}$ from the major transcription starting site, and that it contains two GC boxes. We showed that $\mathrm{Sp} 1$ could bind with these two GC boxes by supershift assays using $\mathrm{Sp} 1$ antibody. In luciferase reporter assays, mutation introduced to one of these GC boxes drastically reduced luciferase activity in HeLa, HepG2, and Chang liver cells. Hence both GC boxes were essential for transcriptional activity of SCOT gene. We compared the SCOT gene promoter activity patterns of the three cell lines in luciferase-reporter assays with the $2.2 \mathrm{~kb}$ and basic promoter region constructs. HeLa cells could be regarded as a extrahepatic cells model and Chang liver cells as a model of hepatic cell lines that gained SCOT expression through dysregulation. HepG2 cells representing SCOT-no expressing hepatoma cells, like normal hepatocytes. These results were based on enzyme assay, immunoblot, and quantitative RT-PCR data. Comparison of luciferase- reporter assay results in these three cell lines suggested that another transcriptional mechanism was important for tissue-specific expression; for example, other transcriptional factors, methylation, or some suppressor sites. Further analyses will be needed to fully understand liver-specific silencing of the SCOT gene.

\section{Acknowledgements}

We thank N. Sakaguchi for technical assistance. This study was supported, in part, by Grants-in-Aid for Scientific Research from the Ministry of Education, Science, Sports, and Culture of Japan, and by the Canadian Institutes of Health Research, Grant MT 10541 to G.M.

\section{References}

Dignam, J.D., Lebovitz, R.M. \& Roeder, R.G. (1983) Accurate transcription initiation by RNA polymerase II in a soluble extract from isolated mammalian nuclei. Nucleic. Acids Res., 11, 1475-1489.

Fenselau, A., Wallis, K. \& Morris, H.P. (1976) Subcellular localization of acetoacetate coenzyme A transferase in rat hepatomas. Cancer Res., 36, 4429-4433.

Fields, A.L.A., Wolman, S.L., Cheema-Dhadli, S., Morris, H.P. \& Halperin, M.L. (1981) Regulation of energy metabolism in Morris hepatoma 7777 and 7800. Cancer Res., 41, 2762-2766.

Fukao, T., Song, X.-Q., Mitchell, G.A., Yamaguchi, S., Sukegawa, K., Orii, T. \& Kondo, N. (1997) Enzyme of ketone body utilization in human tissues: Protein and messenger RNA levels of succinyl-Coenzyme A (CoA): 3-ketoacid CoA transferase and mitochondrial and cytosolic acetoacetyl-CoA thiolases. Pediatr. Res., 42, 498-502.

Fukao, T., Kaneko, H., Birrell, G., Gatei, M., Tashita, H., Yoshida, T., Cross, S., Kedar, P., Watters, D., Khana, K.K., Misko, I., Kondo, N. \& Lavin, M.F. (1999) ATM is upregulated during the mitogenic response in peripheral blood mononuclear cells. Blood, 94, 1998-2006.

Fukao, T., Mitchell, G.A., Song, X.Q., Nakamura, H., KassovskaBratinova, S., Orii, K.E., Wraith, J.E., Besley, G., Wanders, R.J.A., Niezen-Koning, K.E., Berry, G.T., Palmieri, M. \& Kondo, N. (2000) Succinyl-CoA:3-ketoacid CoA transferase (SCOT): Cloning of the human SCOT gene, tertiary structural modeling of the human SCOT monomer, and characterization of three Pathogenic mutations. Genomics, 68, 144-151.

Kassovska-Bratinova, S., Fukao, T., Song, X.-Q., Duncan, A., Chen, H.S., Robert, M.-F., Perez-Cerda, C., Ugarte, M., Chartrand, P., Vobecky, S., Kondo, N. \& Mitchell, G.A. (1996) Succinyl-CoA: 3-ketoacid CoA transferase (SCOT): Human SCOT cDNA cloning and chromosomal mapping and mutation detection in a SCOT-deficient patient. Am. J. Hum. Genet., 59, 519-528.

Lavin, T.N., Baxter, J.D. \& Horita, S. (1988) The thyroid hormone receptor binds to multiple domains of the rat growth hormone 5'-flanking sequence. J. Biol. Chem., 263, 9418 9426.

Lowry, O.H., Rosebrough, N.J., Farr, A.L. \& Randall, R.J. 
(1951) Protein measurement with the Folin phenol reagent. J. Biol. Chem., 193, 265-275.

Mitchell, G.A. \& Fukao, T. (2001) Chapter102 Inborn errors of ketone body catabolism. In: Molecular and Metabolic Bases of Inherited Disease, 8th ed., edited by C.R. Scriver, A.L. Beaudet, W.S. Sly \& D. Valle, NewYork McGrawHill, Inc. pp. 2327-2356.

Miyamoto, T., Suzuki, S. \& Degroot, L.J. (1993) High affinity and specificity of dimeric binding of thyroid hormone receptors to DNA and their ligand-dependent dissociation. Mol. Endcrinol., 7, 224-231.

Page, M.A., Krebs, H.A. \& Williamson, D.H. (1971) Activities of enzymes of ketone-body utilization in brain and other tissues of suckling rats. Biochem. J., 121, 49-53.

Sakazaki, H., Hirayama, K., Murakami, S., Yonezawa, S., Shintaku, H., Sawada, Y., Fukao, T., Watanabe, H., Orii, T. \& Isshiki, G. (1995) A new Japanese case of succinylCoA: 3-ketoacid CoA-transferase deficiency. J. Inherit. Metab. Dis., 18, 323-325.

Sambrook, J., Fritsch, E.F. \& Maniatis, T. (1989) Molecular Cloning: A Laboratory Manual, 2nd Ed., Cold Spring Harbor Laboratory, Cold Spring Harbor, NY.

Song, X.-Q., Fukao, T., Mitchell, G.A., Kassovska-Bratinova, S., Ugarte, M., Wanders, R.J.A., Hirayama, K., Shintaku, H.,
Churchill, P., Watanabe, H., Orii, T. \& Kondo, N. (1997) Succinyl-CoA: 3-ketoacid coenzyme A transferase (SCOT): Development of an antibody to human SCOT and diagnostic use in hereditary SCOT deficiency. Biochim. Biophys. Acta, 1360, 151-156.

Song, X.-Q., Fukao, T., Watanabe, H., Shintaku, H., Hirayama, K., Kassovska-Bratinova, A., Kondo, N. \& Mitchell, G.A. (1998) Succinyl-CoA: 3-ketoacid CoA transferase (SCOT) deficiency: Two pathogenic mutations, V133E and C456F, in Japanese siblings. Hum. Mut., 12, 83-88.

Tashita, H., Fukao, T., Kaneko, H., Teramoto, T., Inoue, R., Kasahara, K. \& Kondo, N. (1998) Molecular basis of selective IgG2 deficiency: The mutated membrane-bound form of gamma2 heavy chain caused complete IgG2 deficiency in two Japanese siblings. J. Clin. Invest., 101, 677-681.

Williamson, D.H., Bates, M.W., Ann Page, M. \& Krebs, H.A. (1971) Activities of enzymes involved in acetoacetate utilization in adult mammalian tissues. Biochem. J., 121, 41-47.

Zhang, W.W., Lindahl, R. \& Churchill, P. (1990) Regulation of succinyl coenzyme A: Acetoacetyl coenzyme A transferase in rat hepatoma cell lines. Cancer Res., 50, 5858-5862. 